\title{
Dispositional Optimism, Affective States and Judgements of Future Life Events
}

\author{
Loredana R. Diaconu-Gherasim, Cornelia Mãirean \\ Alexandru Ioan Cuza University
}

\begin{abstract}
This research examined the relationship between dispositional optimism and judgements of future life events, and whether this relationship is moderated by affective states. An adolescent sample $(N=139,57.6 \%$ girls $)$ was recruited. After filling in the questionnaire for dispositional optimism, the participants were randomly assigned in the experimental conditions in order to induce negative affective states versus control condition. Finally, the participants completed the affective states and judgements of future life events scales. The results indicated that dispositional optimism positively correlated with judgement of positive events, but not with judgements of negative events. We found evidence for affective state as a moderator; the relationship between dispositional optimism and judgements of future positive events was stronger in the control condition compared to the negative affective state condition. The implications of these findings for understanding the relation between personality factors and judgements about future events are discussed.
\end{abstract}

Key words: dispositional optimism, judgements of future events, affective states, adolescents

People are not objective in their judgements about the future, but rather they have the tendency to expect that their future will be better than that of other people (Taylor \& Brown, 1988; Weinstein, 1980). This bias towards positive outcomes appears for various positive and negative events (see Shepperd, Klein, Waters, \& Weinstein, 2013 for a review). These distortions in judgements are related to favourable attitudes and health outcomes (see Armor \& Taylor, 1998 for review) and influence the manner in which people process the information and engage in unhealthy and risky behavior (Radcliffe \& Klein, 2002; Rafaely, Mantsur, BarDavid, \& Meyer, 2011). However, previous lit-

Correspondence concerning this article should be addressed to Loredana R. Diaconu-Gherasim, Department of Psychology, Alexandru Ioan Cuza University, 3 Toma Cozma, Iasi Romania 700554, Email: gloreda@uaic.ro

Received November 4, 2016 erature concerning the role of personality traits, such as dispositional optimism, on the judgements of future events and factors that could explain these relationships, is very limited (see Gherasim, Mairean, \& Rusu, 2016 for an exception). Moreover, to our knowledge, there is no evidence regarding the links between personality characteristics and judgements of future events on adolescent samples.

Adolescence is a critical stage in terms of selecting healthy or unhealthy lifestyle behavior that will continue into adulthood (Martinelli, 1999). Adolescents have the tendency to underestimate the probability of occurrence of different negative events (e.g., automobile accidents, school aggression, divorce, and healthrelated problems; e.g., Arnett, 2000; Chapin \& Coleman, 2012). Understanding the factors related to judgements of future evens represents an important step in making adolescents recognize their personal risk and take self-protective measures (Harris, 2007; Sparks, Harris, \& Raats, 
2003; Weinstein \& Klein, 1996). In order to advance the literature, the first goal of this study was to explore the relationship between dispositional optimism and judgements about the likelihood of experiencing positive and negative life events on a sample of adolescents. Furthermore, the second goal was to investigate whether the relationship between adolescents' dispositional optimism and their judgements of events may be explained by affective states.

\section{Dispositional Optimism}

Dispositional optimism is defined as generalized expectations of positive outcomes that determine the differences in how people cope with adversity and how they feel when they are faced with problems (Carver, Scheier, \& Segerstrom, 2010). A high level of dispositional optimism has been associated with better mental and physical health, as well as with more protective practices, and resilience to stressful life events on samples of adults (see Carver et al., 2010; Rasmussen, Scheier, \& Greenhouse, 2010 for reviews). Previous studies also showed that dispositional optimism is related to various indices of the adolescents' positive adjustment, such as healthcare attitudes, physical and psychological quality of life, or motivation to pursue their goals (e.g., Jones, DeMore, Cohen, O’Connell, \& Jones, 2008; Mannix, Feldman, \& Moody, 2009; Huan, Yeo, Ang, \& Chong, 2006). Recent research suggests that optimism is a modifiable variable that can be developed in adolescents through certain psychological interventions, becoming a stable personality trait throughout adulthood (Mannix et al., 2009; Tusaie \& Patterson, 2006).

There is little empirical evidence about the relationship between dispositional optimism and judgements of future events, and most existent studies explored the role of optimism on judgements of future negative events (Harris \& Hans, 2011). Studies conducted on adult samples showed that the optimists display more positive life evaluations than pessimists and were less likely to expect negative events in the future, such as unsafe work practices, overweight or dental health problems (e.g., Fowler \& Geers, 2015; Gherasim et al., 2016; OginskaBulik \& Juczynski, 2001). Other studies found no association between dispositional optimism and judgements of negative events, such as perceiving the risk of heart attack, obesity or severe acute respiratory syndrome on samples of adults (e.g., Geers et al., 2013; Radcliffe \& Klein, 2002) and undergraduate students (e.g., Ji, Zhang, Usborne, \& Guan, 2004). Moreover, previous literature consistently showed that adults with a high level of dispositional optimism were more likely to expect more positive events to happen to them in the future (e.g., Blackwell et al., 2013; Sharot, Riccardi, Raio, \& Phelps, 2007).

There is no empirical evidence regarding the relationship between dispositional optimism and judgements of events on adolescent samples. To fill this gap in the literature, the first goal of our study is to investigate the relationship between adolescents' dispositional optimism and judgements about the likelihood of experiencing both future positive and negative events. We expected that dispositional optimism would be positively associated with expectations about the likelihood of experiencing future positive events compared to their peers. We also expect that dispositional optimism would be negatively associated with expectations about the likelihood of experiencing future negative events.

\section{Affective States}

Affective states refer to the positive and negative subjective experience occurring at a given moment in time and are conceptualized as two major independent dimensions, positive and negative; a person being able to experi- 
ence negative and positive affects at the same time at different levels of intensity (George, 1996; Watson, Clark, \& Tellegen, 1988). Two dimensions of affective states have been identified: valence and activation (Russell \& Barrett, 1999). While the dimension of valence concerns the positive or negative aspect of an emotional state, the dimension of activation refers to its intensity (e.g., calming or exciting) (Bradley, Cuthbert, \& Lang, 1996). Both positive and negative affective states can be associated with a decrease in activation, no change, or an increase in activation (Cacioppo, Gardner, \& Bernston, 1999) and shape the impulse to respond to reach a goal (Frijda, 1986; Roseman, 1984). Furthermore, high levels of activation may have a motivational role in achieving goals, impacting outcomes to a greater degree than the low levels of activation (Waples \& Connelly, 2008).

Previous studies confirmed the existence of reciprocal influences between emotions and cognitive processes, such as memory, attention, or the ability to solve cognitive problems. It was generally found that positive emotions play a disturbing role in cognitive performance, leading to a lower monitoring effort during a dynamic task and a decline of the correct response rate in a deductive task (e.g., Causse, Pavard, Sénard, Démonet, \& Pastor, 2012). Concerning negative emotions, it is considered that they lead to more systematic information processing. For example, negative emotions stimulate well-known and verified reactions, while positive valence stimulates experimental and creative tendencies while solving a cognitive task (Jurásová, Biela, \& Spajdel, 2014). There is also empirical evidence of the associations of valence of affective states with judgements of future events (see Angie, Connelly, Waples, \& Kligyte, 2011 for review). Overall, the findings have shown that affective states experimentally induced using film clips, brief stories, and memories or imagining oneself in different scenarios, influence the cognitive processes, including the judgements of life events, in a mood-congruent manner (e.g., Ferguson \& Sheldon, 2013; Sparks, Harris, \& Raats, 2003).

Studies investigated the impact of experimentally induced negative affective states compared to a control condition on judgements of future events and used the imagination technique for various negative events (e.g., drinking problems, malfunction of the nervous system or agerelated diseases; Harris, 2007; Rafaely et al., 2011; Sparks et al., 2003). Mixed findings were reported on adult samples. Some studies found that the experimental procedure determined the participants to evaluate future negative events as more likely (e.g., Hepburn, Koundouri, Panopoulou, \& Pantelidis, 2009; Sparks et al., 2003; Vastfjall, Peters, \& Slovic, 2008) and future positive events as less likely (e.g., Hepburn et al., 2009; Vastfjall et al., 2008) to happen to them. It was suggested that when a negative mood is induced, other negative thoughts are activated and the judgements about the future are biased in a mood-congruent direction (Bower, 1981). Contrary, other studies revealed that the adults, after imagining themselves in different negative scenarios, showed a decrease in judgements of future negative events for both themselves and others, compared to the control condition (e.g., Harris, 2007; Rafaely et al., 2011) or compared to neutral or positive conditions (e.g., Chou, Lee, \& Ho, 2007; Fedorikhin \& Cole, 2004). To explain these findings it was suggested that negative moods may prompt more positive self-relevant thoughts and, consequently, mood incongruent response patterns may occur. These responses are considered a coping mechanism used in order to deal with negative feelings, by generating positive cognitions (Forgas \& Ciarrochi, 2002). More research is needed in order to better understand the effect of affective states, experimentally induced by imagining technique, on judgements of future events. 
Adolescence is a time of increased emotional reactivity and sensitivity (Steinberg, 2005). Given the increase in risky choices and behavior during adolescence, it appears that the value of positive and negative information may be exaggerated (Casey, Jones, \& Hare, 2008). There is considerable evidence that on average, adolescents experience more extreme affects (both positive and negative) and more variable mood states in their everyday lives than their adult counterparts (Larson, Moneta, Richards, \& Wilson, 2002). There is no empirical evidence of the relationship between affective states and judgements of future events on samples of adolescents. To advance the literature, the second goal of this study addressed the effect of negative affective states on the judgements of future positive and negative events in a sample of adolescents. To manipulate the adolescents' affective state we used a commonplace and easy-to-imagine negative event (similar with Chambers, Windschitl, \& Suls, 2003; Harris, 2007). Specifically, in this study a scenario related to a negative interrelationship situation was incorporated. A control condition was also added. We expected that the adolescents from a negative mood condition would evaluate the likelihood judgements of future negative and positive events differently, compared to the participants from the control condition. Given the contradictory results regarding the relation between the experimentally induced negative affective state and the judgements about the likelihood of future events, we cannot anticipate specific relations between these variables.

\section{Dispositional Optimism, Affective States and Judgements of Future Events}

Previous literature suggests that the relationship between dispositional optimism and judgements of future events may be partially due to affective states (Radcliffe \& Klein, 2002), however, only two studies conducted on adult samples investigated these relationships, and mixed findings were reported. One study indicated that affective states did not moderate the association between dispositional optimism and judgements of negative future events (Kuipmer et al., 2009). The second study found that the associations between dispositional optimism and the judgements of future positive events, but not for negative events, were significantly weaker in intensity in the positive affective state condition, compared to the negative affective state or control conditions (Gherasim et al., 2016). Our study assessed whether the relationship between dispositional optimism and judgements of future events is moderated by affective states on an adolescent sample.

This assumption was investigated using imagination in a negative scenario condition in order to accentuate the participants' affective states versus a control condition. Thus, we assessed the impact of the negative affective state, using two conditions: negative experimental and control conditions, looking at the link between optimism and judgements when it comes to the probability of future events on a sample of high school adolescents. In order to check the impact of the experimental manipulation, the participants' affective states were measured after the experimental manipulation. Considering previous research (Chou et al., 2007; Hepburn et al., 2009), we supposed that the negative mood condition would rather decrease the positive association between dispositional optimism and the judgements about future positive events, and increase the strength of the association between optimism and judgements about negative events, compared to the control condition.

To induce the negative affective state, we have used an imagination procedure that was previously used to induce negative affective states only on samples of adults in order to influence their judgements of future events (e.g., Sparks et al., 2003). Thus, we wanted to expand its validity to a sample of adolescents. 
This procedure asked to the participants to imagine a negative event (and sometimes to write about it) and then to estimate the likelihood of future negative events.

\section{Method}

\section{Participants}

One hundred and thirty nine high school students ( 80 girls), aged between 15 and 18 years old, voluntarily participated in the study. The participants were enrolled in two public urban high schools with a humanistic profile. Prior to the adolescents' participation, parents signed informed consent statements. Also, permissions for the study were obtained from the school authorities. The adolescents' mean age was $16.67(S D=.93)$ years. The general distribution of students in classes was: $20.1 \%$ ninth graders, $37.4 \% 10$ th graders and $42.4 \% 11$ th graders.

\section{Materials}

Dispositional Optimism. The 6-item questionnaire of The Life Orientation Test - Revised (LOT-R; Scheier, Carver, \& Bridges, 1994) was used to measure the adolescents' optimism level. In this study we used only the key items (three worded positively and three worded negatively), but not the filler items from the original scale (similarly to Ji et al., 2004). The items were rated on a 5-point Likert scale, from $0=$ strongly disagree to $4=$ strongly agree. The indices revealed an acceptable fit of the single factor solution: $\chi^{2}(9, N=138)=16.10, p=.065 ; \chi^{2} / \mathrm{df}=1.17, \mathrm{NFI}$ $=.87 ; \mathrm{CFI}=.84 ; \mathrm{RMSEA}=.076$. Therefore, we used a single summative index method for scoring the LOT-R scale; higher scores indicated a higher level of dispositional optimism. The internal consistency of our sample was acceptable (.68) and similar to the indices revealed by other previous studies (Blackwell et al., 2013;
Scheier et al., 1994). Previous literature shows that the scale has good validity, being associated with subjective well-being and fewer health-related problems (e.g., Forgeard \& Seligman, 2012).

Affective State Induction. There were two experimental conditions. In order to select the scenarios for the negative condition, we conducted a pre-test on a sample of high school adolescents $(N=20)$, who had the task to report negative events that happened to them in the past year. The event with the higher frequency was selected: an argument with one of their best friend. Further, other participants $(N=30)$ received the event and had the task to list five negative affects that an adolescent could feel in that situation. Based on the adolescents' answers, thirteen negative affective states were selected and used to describe what the main character feels. It was also used for the evaluation of target affective states during the experimental manipulation. To induce the negative mood, we applied a procedure used less frequently, based on previous literature, revealing that the repetition of the imagination task may influence the participants' judgements of future events (e.g., Anderson, 1983; Sparks et al., 2003). Thus, in order to emphasize the negative mood, the adolescents initially read the list of emotions that the target person felt after the negative events and then they rated the intensity of these negative emotions that they would have felt in the main character's place. Thus, in the negative condition the students received the following scenario: "M. argued with his best friend. After this argument, M. felt the following emotions: anger, irritability, irascibility, fury, blues, sadness, disappointment, isolation, marginalization, frustration, betrayal, felt alone and misunderstood by the people around".

The participants were randomly distributed into two groups: condition negative mood versus control condition. The adolescents were 
initially split into small groups (containing 5-6 participants) and then these small groups were randomly distributed in experimental or control conditions. Each group worked with a research assistant. The application was simultaneously made in class in groups of 2 to 4 adolescents (some of them being randomly distributed in the control condition and others in the experimental condition) in the same room. The participants were asked to read the scenario and to imagine themselves in the place of the main character, and then to rate the intensity of the negative affects that they would have felt in the main character's place, using a 10-point Likert scale (from $1=$ not at all to $10=$ very much). We could not measure the participants' affective state before the experimental manipulation of the participants' mood (which took place in just a few minutes) because statistical regression, familiarity with the items of PANASSF scale or even memorizing the answers of the initial application of the scale may have influenced the adolescents' evaluations of the affective state after the experimental manipulation.

To neutralize the effect of the experimental manipulation, the participants from the negative condition viewed a happy film at the end of experimental condition. The selection of the film clip, it was based on a pilot study, was used in previous research (Chou et al., 2007). After viewing, in a random order, a series of six positive 4-minute film clips, 75 students ( $65 \%$ females, Mage $=16.8, S D=.80$ ) reported their mood using the PANAS-SF; Thompson, 2007) on a 7-point scale ranging from 0 (not at all) to 6 (very much). We selected one film, The Colours, that had a significantly more positive effect than a negative one, $t(74)=5.48, p .001$.

Affective States. The participants' affective states were measured using the Positive and Negative Affect Schedule Short Form (PANASSF; Thompson, 2007). This version consisted of two pairs of 5 adjectives rated on a 7-point
Likert scale, from 0 (not at all) to 6 (very much). The composite average scores were computed for each dimension; higher scores indicated a higher level of positive and negative affectivity, respectively. The reliability coefficients for our sample were $\alpha=.85$ for the positive affective states scale, and $\alpha=.91$ for negative affective states.

Judgement of Life Events. The 24-item questionnaire The Judgement of Life Events Scale (JLE; Zelenski \& Lasen, 2002), translated into Romanian by Gherasim et al. (2016), was used to assess the likelihood of judgements of future positive and negative events. In this study we used only 9 positive events (e.g., "What are the chances that you would win the lottery if you played regularly?") and 9 negative events (e.g., "What are the chances that you will be involved in a serious car accident in the next 5 years?"). The participants rated the likelihood of experiencing these events compared with their peers, on a scale from $0 \%=$ very unlikely to $100 \%=$ very likely. Indices of confirmatory factor analyses showed an acceptable fit of the positive and negative subscales: $\chi^{2}(131, N=$ $138)=200.95, p=.001 ; \chi^{2} / \mathrm{df}=1.53, \mathrm{NFI}=.76$; $\mathrm{CFI}=.86$; RMSEA $=.062$. Composite mean scores were computed for each scale, higher scores indicating a higher likelihood of judgements of future positive and negative events, respectively. The internal consistency of our sample was good (.74 for positive and .79 for negative events).

\section{Procedure}

The study was conducted during school hours, under the supervision of a teacher or a school counsellor. The investigation was presented as an exploration of the adolescents' attitude towards different situations. Initially, the participants provided information about their age and gender and filled in the pre-experimental questionnaire measuring dispositional 
optimism. Then, they were randomly assigned in one of two experimental conditions - negative affective state condition $(n=75)$ and control condition $(n=64)$. Each group worked with a research assistant. The application was simultaneously made in class in groups of 2 to 4 adolescents (some of them being randomly distributed in the control condition and others in the experimental condition) in the same room. Stimuli were not used to evoke a neutral emotional state for the participants from the control condition. Consecutively, the adolescents filled in the scales measuring the affective state and the judgements of future life events scales. Since for the participants from the control groups the application was short, these adolescents left the room earlier. Finally, the participants from the negative condition remained in class and were asked to view a happy film in order to neutralize the effect of the experimental manipulation.

\section{Results}

The statistical findings are presented in two parts. Firstly, we analyzed whether the participants' gender and age are covariates and then whether the experimental manipulation had an impact on the adolescents' answers. Secondly, the associations between optimism and judgements of future events were assessed. Thirdly, the moderating role of affective states in the relationship between optimism and judgements of future events was explored.

\section{Preliminary Analysis and Manipulation Check}

A multivariate factorial analysis of covariance (MANCOVA), using experimental manipulation as a fixed factor and dispositional optimism, and judgements of future positive and negative events as dependent variables, indicated that the participants' gender and age did not covariate $F \mathrm{~s}=.67$ and .56 , all $p \mathrm{~s}>.05$. Therefore, the other analyses were conducted without controlling these demographic variables.

To examine the interaction between affective state manipulation and judgements of future events, an analysis of variance with repeated measures (ANOVA) was conducted with affective state conditions (negative vs. control) as a between-subjects factor, and judgements of future events (positive vs. negative events) as a within factor. There was a significant main effect of the repeated measure of judgements of life events, $F(1,211)=242.78, p<.001, \eta_{\mathrm{p}}{ }^{2}=$ .63 ; the participants, regardless of the experimental condition, judged that positive events, $M=54.12, S D=17.51$, were more likely to happen to them in the future than negative events, $M=25.91, S D=15.46$. The results also indicated a significant affective state $\mathrm{x}$ mood manipulation interaction effect, $F(1,211)=19.18$, $p<.01, \eta_{\mathrm{p}}{ }^{2}=.12$. Specifically, the adolescents from the control condition reported that future positive events are more likely, $M=57.21, S D=$ 16.90, whereas future negative events were less likely, $M=20.25, S D=13.11$, to happen to them compared to the adolescents from the negative mood condition, $M=51.48, S D=17.70 ; M=$ $30.74, S D=15.74$, respectively. Furthermore, in both negative, $M=51.48, S D=17.7$, and control, $M=57.21, S D=16.9$, conditions, the adolescents have the tendency to expect more positive events but less negative events in the future, $M=30.74, S D=15.74$, and $M=20.25$, $S D=13.11$, respectively. Finally, there was no significant effect of the mood manipulation on overall judgements of future events, $F(1,148)=1.40, p>.05$.

As a manipulation check, the participants' affective states were measured after the manipulation of the scenarios. The $t$ tests indicated a significant main effect of the affective state induction on both positive and negative affective states, $t(137)=3.20$ and 14.96 , all $p s<.001$. The adolescents from the negative affective 
state condition had higher levels of positive $M=3.89, S D=1.52$ and negative $M=4.62, S D=$ 1.41 affective states, compared to those from the control condition, $M=3.10, S D=1.36$ and $M=1.41, S D=1.05$, respectively. An explanation of these results could be that the induction of the negative states could determine the participants to 'correct' their mood bias, when they are aware of their mood, by adjusting their emotions in the opposite direction of the assumed mood influence (McFarland et al., 2003). As McFarland et al. (2003) suggested, this tendency was verified simply by asking people to report their mood using the PANAS scale.

\section{Correlations}

Correlational analyses indicated that dispositional optimism was significantly positively associated with expectations about the likelihood experiencing future positive events, $r=$ $.17, p<.01$, but was non-significantly associated with expectations about the likelihood experiencing future negative events, $r=-.06, p>$ .05 .

\section{Testing for Moderation}

For testing our hypothesized model, asserting that affective states could moderate the relation between dispositional optimism and judgements of future events, we applied the Structural Equation Modeling. For assessing the moderation effect, we applied a multi-group analysis approach using critical ratios to identify significant differences between the negative and control condition on each path (Byrne, 2009). For the SEM model of direct and moderation effects, estimates were derived using maximum likelihood estimations and an overall model fit was assessed using the normative fit index (NFI), the comparative fit index (CFI) and the root mean square residual (RMSEA) (Hu \& Bentler, 1999). The fit for our overall model was good: $\chi^{2}(2)=1.27, p=.528 ; \chi^{2} / \mathrm{df}=0.63 ; \mathrm{NFI}=$ $.95 ; \mathrm{CFI}=.99$; $\mathrm{RMSEA}=<.001,90 \%$ CI [.000; .148]. As assumed, dispositional optimism significantly predicted judgements of future positive events $(\beta=.17, p=.044)$ but did not predict the judgement of future negative events $(\beta=$ $-.06, p=.455)$.

Further, we tested whether the links between dispositional optimism and judgements of future positive events differ in strength, when conditioned by an affective state. In order to test the presumed moderations, we used critical ratios ( $z$-scores) comparisons between groups on each specified path. A significant difference is flagged by a critical ratio value greater than 1.65 for the $90 \%$ confidence, 1.96 for $95 \%$, and 2.58 for $99 \%$. Comparing the regression weights for the path between optimism and judgements of positive events, the results indicated that the relationship in the negative affective mood condition $(b=-.26, p=.595)$ was non-significant and significantly weaker com-

Table 1 Critical ratios comparisons for multi-group analysis

\begin{tabular}{lcccccc}
\hline & \multicolumn{2}{c}{ Negative } & \multicolumn{2}{c}{ Control } & \multirow{2}{*}{$Z$ score } \\
\cline { 2 - 5 } & Estimate & $p$ & Estimate & $p$ & \\
\hline $\begin{array}{l}\text { Dispositional optimism } \rightarrow \\
\text { Judgements of positive events }\end{array}$ & -0.26 & 0.595 & 2.55 & $<.001$ & $-3.826^{* * *}$ \\
\hline $\begin{array}{l}\text { Dispositional optimism } \rightarrow \\
\text { Judgements of negative events }\end{array}$ & -0.23 & 0.604 & -0.26 & 0.583 & 0.053 \\
\hline
\end{tabular}

Note . Negative $=$ negative affective state condition; Control $=$ control condition

$* * * p<.001$ 
pared to the control condition $(b=2.55, p<$ $.001 ; z=-3.82, p<.001)$. More precisely, when the participants experienced an elevated negative affective state, the judgements of future positive events were not influenced by dispositional optimism, compared to the judgements they made in the control condition. There were no significant differences between the negative affective state $(b=-.23, p=.604)$ and the control condition $(b=-.26, p=.583 ; z=0.05, p>$ .05 ) for the path between optimism and judgements of future negative events. The pattern of results for the multi-group comparisons is presented in Table 1.

\section{Discussion}

The current study explored the relationship of dispositional optimism and affective states with judgements of future events on an adolescent sample. Zero-order correlation indicated that dispositional optimism was significantly positively associated with judgements of future positive events. These findings confirm the previous results found on adult samples, showing that optimistic individuals were more likely to expect more positive events to happen to them in the future (e.g., Blackwell et al., 2013; Sharot et al., 2007). In line with the studies reported on adult samples (e.g., Ji et al., 2004; Radcliffe \& Klein, 2002), dispositional optimism did not significantly correlate with the likelihood of judgements of future events. All these findings suggest that, although a high level of optimism increases the beliefs that future positive events are more likely to happen in the future, it did not implicitly generate the beliefs that negative events are less likely to occur in the future. In other words, the core of optimism concerning the reflexive tendency to judge positive outcomes as more likely did not imply the fact that people also consider negative events as less likely (Carver et al., 2010).
The results indicated a significant effect of the experimental manipulation on the judgements of future events. As expected, the adolescents from the negative mood condition reported that negative events are more likely and positive life events less likely to happen to them in the future, compared to the adolescents from control condition. These findings are in line with previous studies conducted on adults, indicating that the participants, after imagining themselves in a negative situation, report future negative events as more likely and positive events as less likely to happen to them in the future (Hepburn et al., 2009; Sparks et al., 2003; Vastfjall et al., 2008).

The second goal of the study was to investigate whether the association between dispositional optimism and judgements of future events is moderated by affective states. We found some evidence for the moderating effect of affective states on the relationship between optimism and judgements of future positive events. Specifically, the association between optimism and judgements of future positive events was significant in the control condition, but not in the negative affective state condition. In the control condition, where the negative affective state was not accentuated, a high level of optimism led to a greater tendency to evaluate future positive events as more likely to happen to them. This tendency of optimists to expect more positive events in the future is documented in previous studies conducted on samples of adults (e.g., Blackwell et al., 2013; Sharot et al., 2007). Moreover, our finding paralleled those indicating no influences of negative affective states on adults' judgements of future positive events (Sparks et al., 2003). These results may suggest that a negative mood may determine a more systematic processing of information and may reduce the level of decision-making (Forgas, 2013).

Furthermore, the affective states did not moderate the relationship between optimism and 
judgements of future negative events. For all participants, dispositional optimism was not related to likelihood judgements of future negative events. The low level of perceived personal relevance of the events could explain these findings (Geers et al., 2013; Schwarz, 1998). Specifically, people have the tendency to judge events as less likely to happen to them if these events are not personally relevant. Since few studies have examined the relationship between optimism and judgements of future events, and no other study explored the moderating role of experimentally induced affective states in this relationship, we cannot compare our results with other empirical findings.

When interpreting these findings, certain limitations should be noted. Firstly, we did not measure the adolescents' initial mood (before the affective state induction) and it is less clear whether the differences between groups reflect the effect of experimental manipulation or the initial differences between groups, in terms of affective state. Future studies should consider the participants' initial affective states (e.g., level of depressive symptoms) that might influence the impact of subsequent experimental manipulation and judgements of future events (Hepburn et al., 2009). Secondly, the participants' ratings of the intensity of these negative emotions (e.g., sadness and irritability) that they would have felt in the main character's place were not analyzed, so we cannot specify if these negative emotions were similarly evaluated or not by the participants. Future studies should consider a more detailed measure of the impact of experimental manipulation on the participants' affective states. Thirdly, we did not assess individual differences in the ability to use imagination in daily life. Given that mental imagery allows people to make plans for the future (Pearson, Naselaris, Holmes, \& Kosslyn, 2015), the judgement of future events may depend on the ability to generate vivid images of those events. Moreover, the imagination technique used for manipulating the affective states may be more effective for the participants with a high level of imagination. Fourthly, perceiving control for future events needs to be considered in future studies, as it allows people to make predictions for the future. When a person perceives that they have no control over an event, they are less likely to anticipate that the event will happen in the future (Shepperd et al., 2013). Fifth, future studies should also consider the use of a positive affective state condition using the imagination technique, in order to have a complete picture of the effect of affective states on the relationship between dispositional optimism and judgements of future events.

Our study showed that a high level of dispositional optimism combined with a low level of negative affect is essential for the adolescents' anticipating a positive future. These findings suggest that targeted interventions for increasing adolescents' optimism should take into account imagining a positive future, as previous studies indicated, but also negative events (Blackwell et al., 2013; Malouff \& Schutte, 2016). Future studies should investigate whether the methodology used in this research is related to unrealistic optimism or an optimism bias about risky behavior, and thus, could help researchers to find factors that could reduce the adolescents' unhealthy and risky behavior.

The current findings advance the literature on the adolescents' dispositional optimism, affective states and their judgements about future events. In summary, we found that dispositional optimism is positively related to judgements of future positive life events. We demonstrated that affective states may explain the power of the relationship between dispositional optimism and the adolescents' judgements of events. The field would benefit from experimental studies designed to clarify the potential impact of imagining positive events on adolescents' evaluation of events. Additionally, future studies should evaluate other mechanisms 
that may be responsible for the relationship between optimism and the adolescents' judgements about future events.

\section{References}

Anderson, C. A. (1983). Imagination and expectation: The effect of imagining behavioral scripts on personal intentions. Journal of Personality and Social Psychology, 45(2), 293-305.

Angie, A. D., Connelly, S., Waples, E. P., \& Kligyte, V. (2011). The influence of discrete emotions on judgement and decision-making: A meta-analytic review. Cognition \& Emotion, 25(8), 1393-1422.

Armor, D. A., \& Taylor, S. E. (1998). Situated optimism: Specific outcome expectancies and self-regulation. In M. P. Zanna (Ed.), Advances in experimental social psychology (Vol. 30, pp. 309-379). New York: Academic Press.

Arnett, J. (2000). Optimistic bias in adolescent and adult smokers. Addictive Behaviors, 25(4), 625-632.

Blackwell, S. E., Rius-Ottenheim, N., SchultevanMaaren, Y., Carlier, I., Middelkoop, V., Zitman, F., Spinhoven, F., Holmes, E., Giltay, E. (2013). Optimism and mental imagery: A possible cognitive marker to promote well-being? Psychiatry Research, 206, 56-61.

Bower, G. H. (1981). Mood and memory. American Psychologist, 36(2), 129-138.

Bradley, M. M., Cuthbert, B. N., \& Lang, P. J. (1996). Picture media and emotion: Effects of a sustained affective context. Psychophysiology, 33(6), 662670 .

Byrne, B. M. (2009). Structural equation modeling with AMOS: Basic concepts, applications, and programming (2nd ed.). New York, NY: Taylor and Francis Group.

Cacioppo, J. T., Gardner, W. L., \& Berntson, G. G. (1999). The affect system has parallel and integrative processing components: Form follows function. Journal of Personality and Social Psychology, 76(5), 839-855.

Carver, C. S., Scheier, M. F., \& Segerstrom, S. C. (2010). Optimism. Clinical Psychology Review, 30, 879-889.

Casey, B. J., Jones, R. M., \& Hare, T. A. (2008). The adolescent brain. Annals of the New York Academy of Sciences, 1124(1), 111-126.

Causse, M., Pavard, B., Senard, J. M., Démonet, J. F., $\&$ Pastor, J. (2012). Positive and negative emotion induction through avatars and its impact on reasoning performance: Cardiovascular and pupillary correlates. Studia Psychologica, 54(1), 37-51.

Chambers, J. R., Windschitl, P. D., \& Suls, J. (2003). Egocentrism, event frequency, and comparative optimism: When what happens frequently is "more likely to happen to me". Personality and Social Psychology Bulletin, 29, 1343-1356.

Chapin, J. R. \& Coleman, G. (2012). Optimistic bias about dating/relationship violence among teens. Journal of Youth Studies, 15(5), 645-655.

Chou, K., Lee, T., \& Ho, A. (2007). Does mood state change risk-taking tendency in older adults? Psychology and Aging, 22(2), 310-318.

Fedorikhin, A., \& Cole, C. A. (2004). Mood effects on attitudes, perceived risk and choice: Moderators and mediators. Journal of Consumer Psychology, 14, 212.

Ferguson, Y. L., \& Sheldon, K. M. (2013). Trying to be happier really can work: Two experimental studies. The Journal of Positive Psychology, 8(1), 23-33.

Forgas, J. P., \& Ciarrochi, J. V. (2002). On managing moods: Evidence for the role of homeostatic cognitive strategies in affect regulation. Personality and Social Psychology Bulletin, 28(3), 336-345.

Forgeard, M. J. C., \& Seligman, M. E. P. (2012). Seeing the glass half full: A review of the causes and consequences of optimism. Pratiques Psychologiques, 18(2), 107-120.

Fowler, S. L., \& Geers, A. L. (2015). Dispositional and comparative optimism interact to predict avoidance of a looming health threat. Psychology \& Health, 30(4), 456-474.

Frijda, N. H. (1986). The emotions. New York: Cambridge University Press.

Geers, A. L., Wellman, J. A., \& Fowler, S. L. (2013). Comparative and dispositional optimism as separate and interactive predictors. Psychology \& Health, $8(1), 30-48$.

George, J. M. (1996). Group affective tone. In M. A. West (Ed.), Handbook of work group psychology (pp. 77-93). Chicester, UK: Wiley.

Gherasim, L. R., Măirean, C., \& Rusu, A. (2016). Dispositional optimism and judgments of future life events: Affective states as moderators. Journal of Happiness Studies, 17(3), 1015-1031.

Harris, A. J. L., \& Hahn, U. (2011). Unrealistic optimism about future life events: A cautionary note. Psychological Review, 118, 135-154.

Harris, P. (2007). The impact of perceived experience on likelihood judgments for self and others: An experimental approach. European Journal of Social Psychology, 37, 141-151.

Hepburn, C., Koundouri, P., Panopoulou, E., \& Pantelidis, T. (2009). Social discounting under uncertainty: A cross-country comparison. Journal of Environmental Economics and Management, 57, 140-150.

Huan, V. S., Yeo, L. S., Ang, R. P., \& Chong, W. H. (2006). The influence of dispositional optimism and 
gender on adolescents' perception of academic stress. Adolescence, 41(163), 533-546.

Jones, T., DeMore, M., Cohen, L., O’Connell, C., \& Jones, D. J. (2008). Childhood healthcare experience, healthcare attitudes, and optimism as predictors of adolescents' healthcare behavior. Journal of Clinical Psychology in Medical Settings, 15, 234240 .

Ji, L. J., Zhang, Z., Usborne, E., \& Guan, Y. (2004), Optimism across cultures: In response to the severe acute respiratory syndrome outbreak, Asian Journal of Social Psychology, 7, 25-34.

Jurásová, K. I., Biela, A., \& Spajdel, M. (2014). Impact of emotional valence and different source problem conditions on the resolution of analogical target problems. Studia Psychologica, 56(2), 99-107.

Kluemper, D., Little, L., \& DeGroot, T. (2009). State or trait: Effects of state optimism on job-related outcomes. Journal of Organizational Behavior, 30, 209-231.

Larson, R. W., Moneta, G., Richards, M. H., \& Wilson, S. (2002). Continuity, stability, and change in daily emotional experience across adolescence. Child Development, 73(4), 1151-1165.

Mannix, M. M., Feldman, J. M., \& Moody, K. (2009). Optimism and health-related quality of life in adolescents with cancer. Child: Care, Health and Development, 35(4), 482-488.

Martinelli, A. M. (1999). An explanatory model of variables influencing health promotion behaviors in smoking and nonsmoking college students. Public Health Nursing, 16, 263-269.

McFarland, C., White, K., \& Newth, S. (2003). Mood acknowledgment and correction for the mood congruency bias in social judgment. Journal of Experimental Social Psychology, 39, 483-491.

Morina, N., Deeprose, C., Pusowski, C., Schmid, M., \& Holmes, E. A. (2011). Prospective mental imagery in patients with major depressive disorder or anxiety disorders. Journal of Anxiety Disorders, 25(8), 1032-1037.

Oginska-Bulik, N., \& Juczynski, Z. (2001). Coping with stress as a determinant of reducing overweight in women, Studia Psychologica, 43(1), 23-31.

Pearson, J., Naselaris, T., Holmes, E. A., \& Kosslyn, S. M. (2015). Mental imagery: Functional mechanisms and clinical applications. Trends in Cognitive Sciences, 19(10), 590-602.

Radcliffe, N. M., \& Klein, W. M. P. (2002). Dispositional, unrealistic, and comparative optimism: Differential relations with knowledge and processing of risk information and beliefs about personal risk. Personality and Social Psychology Bulletin, 28, 836-846.

Rafaely, V., Mantsur, A., Bar-David, L., \& Meyer, J. (2011). Saving for a rainy day? Comparative opti- mism about disability in old age. Journal of Applied Social Psychology, 41(5), 1059-1082.

Rasmussen, H. N., Scheier, M. F., \& Greenhouse, J. B. (2009). Optimism and physical health: A meta-analytic review. Annals of Behavioral Medicine, 37, 239-256.

Russell, J. A., \& Barrett, L. F. (1999). Core affect, prototypical emotional episodes, and other things called emotion: Dissecting the elephant. Journal of Personality and Social Psychology, 76(5), 805819.

Scheier, M. F., Carver, C. S., \& Bridges, M. W. (1994). Distinguishing optimism from neuroticism (and trait anxiety, self-mastery, and self-esteem): A reevaluation of the Life Orientation Test. Journal of Personality and Social Psychology, 67, 1063-1078.

Schwarz, N. (1998). Accessible content and accessibility experiences: The interplay of declarative and experiential information in judgment. Personality and Social Psychology Review, 2, 87-99.

Sharot, T., Riccardi, A. M., Raio, C. M., \& Phelps, E. A. (2007). Neural mechanisms mediating optimism bias. Nature, 450, 102-105.

Shepperd, J. A., Klein, W. M. P., Waters, E. A., \& Weinstein, N. D. (2013). Taking stock of unrealistic optimism. Perspectives on Psychological Science, 8(4), 395-411.

Sparks, P., Harris, P. R., \& Raats, M. (2003). Imagining and explaining hypothetical scenarios: Mediational effects on the subjective likelihood of healthrelated Outcomes. Journal of Applied Social Psychology, 33(4), 869-887.

Steinberg, L. (2005). Cognitive and affective development in adolescence. Trends in Cognitive Sciences, $9(2), 69-74$.

Taylor, S. E., \& Brown, J. D. (1988). Illusion and wellbeing: A social psychological perspective on mental health. Psychological Brown Bulletin, 103, 193-210.

Tusaie, K. R., \& Patterson, K. (2006). Relationships among trait, situational, and comparative optimism: Clarifying concepts for a theoretically consistent and evidence-based intervention to maximize resilience. Archives of Psychiatric Nursing, 20(3), 144150 .

Thompson, E. R. (2007). Development and validation of an internationally reliable short-form of the positive and negative affect schedule (PANAS). Journal of Cross-Cultural Psychology, 38, 227-242.

Vastfjall, D., Peters, E., \& Slovic, P. (2008). Affect, risk perception and future optimism after the tsunami disaster. Judgment and Decision Making, 3(1), 64-72.

Waples, E. P., \& Connelly, S. (2008). Leader emotions and vision implementation. In R. A. Humphrey (Ed.), Affect and emotions: New directions in manage- 
ment theory and research (pp. 67-96). Information Age Publishing: Charlotte, NC.

Watson, D., Clark, L. A., \& Tellegen, A. (1988). Development and validation of brief measures of positive and negative affect: The PANAS Scales. Journal of Personality and Social Psychology, 47, 1063-1070.

Weinstein, N. D. (1980). Unrealistic optimism about future life events. Journal of Personality and Social Psychology, 39, 806-820.
Weinstein, N. D., \& Klein, W. M. (1995). Resistance of personal risk perceptions to debiasing interventions. Health Psychology, 14, 132-140.

Zelenski, J. M., \& Larsen, R. J. (2002). Predicting the future: How affect-related personality traits influence likelihood judgments of future events. Personality and Social Psychology Bulletin, 28, 10001010 . 